\title{
ALTERNATIF PENGGUNAAN SERAT ECENG GONDOK (EICHHORNIA CROSSIFES) SEBAGAI BAHAN TAMBAH PADACAMPURAN BETON DITINJAU TERHADAP KUAT TEKANNYA
}

\author{
Budi Tri Cahyono ${ }^{1}$;Rio Rahma Dhana ${ }^{2}$ \\ ${ }^{1,2}$ Fakultas Teknik Universitas Islam Lamongan \\ email : Tricahyono_budi@yahoo.com;dkartika27@gmail.com
}

\begin{abstract}
The purpose of this study is to find out and analyze the addition of water hyacinth fiber as a mixture on concrete. Data analysis methods begin with the investigation of cement material, fine aggregate, coarse aggregate, and water hyacinth material. Concrete is added with water hyacinth fiber with addition variations of $0 \%, 1 \%, 3 \%$ and $5 \%$. Test object used in the form of a cylinder with size ø $15 \mathrm{~cm} \times 30 \mathrm{~cm}$. Concrete mix design uses ASTM method. In the process of making water hyacinth fiber begins with cutting the water hyacinth by $3-5 \mathrm{~cm}$, then milling it into fiber. The next step is drying into the sun and then into the oven at $150^{\circ} \mathrm{C}$. From the results of the research conducted at the Civil Engineering Laboratory of Lamongan Islamic University, the results showed that there was a decrease in strength in the variation of the addition of water hyacinth $1 \%$ and $3 \%$ but experienced an increase in the 5\% variation. It is known that the correlation of concrete compressive strength at 28 days is $0 \%$ at 86.27 $\mathrm{Kg} / \mathrm{cm} 2,1 \%$ at $60.66 \mathrm{Kg} / \mathrm{cm} 2,3 \%$ at $55.27 \mathrm{Kg} / \mathrm{cm} 2$ and $5 \%$ at $57.97 \mathrm{Kg} / \mathrm{cm} 2$.
\end{abstract}

Keywords: water hyacinth, concrete, compressive strength

\begin{abstract}
ABSTRAK
Tujuan dari penelitian ini adalah untuk mengetahui dan menganalisis penambahan serat eceng gondok sebagai campuran pada beton. Metode analisis data dimulai dengan investigasi bahan semen, agregat halus, agregat kasar, dan bahan eceng gondok. Beton ditambahkan dengan serat eceng gondok dengan variasi penambahan $0 \%, 1 \%, 3 \%$ dan $5 \%$. Benda uji yang digunakan berupa silinder dengan ukuran ø $15 \mathrm{~cm} \times 30 \mathrm{~cm}$. Desain campuran beton menggunakan metode ASTM. Dalam proses pembuatan serat eceng gondok diawali dengan memotong eceng gondok sebanyak 3-5 cm, kemudian digiling menjadi serat. Langkah selanjutnya adalah menjemur ke matahari dan kemudian ke oven pada $150{ }^{\circ} \mathrm{C}$. Dari hasil penelitian yang dilakukan di Laboratorium Teknik Sipil Universitas Islam Lamongan, hasil penelitian menunjukkan bahwa terdapat penurunan kekuatan variasi penambahan eceng gondok 1\% dan 3\% tetapi mengalami peningkatan variasi $5 \%$. Diketahui bahwa korelasi kuat tekan beton pada 28 hari adalah $0 \%$ pada $86,27 \mathrm{Kg} / \mathrm{cm} 2,1 \%$ pada $60,66 \mathrm{Kg} / \mathrm{cm} 2,3 \%$ pada $55,27 \mathrm{Kg} / \mathrm{cm} 2$ dan $5 \%$ pada $57,97 \mathrm{Kg} / \mathrm{cm} 2$.
\end{abstract}

Kata Kunci: eceng gondok, beton, kuat tekan

\section{PENDAHULUAN}

Kata beton dalam bahasa inggris berasal dari bahasa Latin concretus yang berarti tumbuh 
bersama atau menggabungkan menjadi satu. Dalam bahasa Jepang digunakan kata kotau-zai, yang arti harafiahnya material-material seperti tulang; mungkin karena agregat mirip tulangtulang hewan. (Tjokrodimulyo, 2007) Beton merupakan pencampuran dari semen, agregat halus, agregat kasar dan air dengan suatu perbandingan tertentu. Jika ingin membuat beton berkualitas baik, dalam arti memenuhi persyaratan yang lebih ketat karena tuntutan yang lebih tinggi, maka harus diperhitungkan dengan seksama cara-cara memperoleh adukan beton(beton segar/fresh concrete) yang baik dan beton (beton keras / hardened concrete) yang dihasilkan juga baik. Beton yang baik ialah beton yang kuat, tahan lama/awet, kedap air, tahan aus, dan sedikit mengalami perubahan volume (kembang susutnya kecil). Dari penelitihan terdahulu ternyata eceng gondong ini memiliki kandungan senyawa kimia yang sangat berperan penting dalam pembuatan semen, Penggunaan bahan tambahan kimia sesuai kebutuhan untuk memperkuat hasil beton pun dilakukan demi menghasilhan beton yang berkualitas baik. Eceng gondok dimanfaatkan untuk dibuat serbuk yang akan digunakan sebagai campuran pembuatan beton (Hidayat,2011). Tujuan Penelitian ini adalah Untuk mengetahui fungsi dan pembuatan eceng gondok sebagai bahan serat selulosa yang digunakan sebagai bahan tambah untuk meningkatkan kuat tekan beton.

\section{METODE PENELITIAN}

Penelitian ini menggunakan metode penelitian eksperimental laboratorium yaitu mengadakan kegiatan percobaan untuk mengadakan suatu hasil. Tujuan eksperimen ini yaitu untuk membandingkan hasil yang telah didapat dalam penelitian dengan syarat - syarat yang ada. Waktu dan tempat penelitian ini akan dilakukan di Laboratorium Teknik Sipil Universitas Islam Lamongan J1. Veteran No.53 A Lamongan. Penelitian ini dilakukan mulai bulan Februari 2018 sampai selesai.

\subsection{Pelaksanaan Penelitian}

Bahan

Bahan - bahan yang digunakan dalam pembuatan benda uji adalah:

a. Semen Portland

b. Agregat Kasar (Kerikil)

c. Agregat Halus (Pasir)

d. Serat Alami Eceng gondok e. Air

Peralatan

Peralatan yang dibutuhkan dalam penelitian

ini adalah : 
a. Alat pencampur bahan :

- Concrete mixer

- Sekop /sendok semen

b. Cetakan silinder beton

c. Mesin tekan hidrolis untuk menguji kuat tekan beton

\subsection{Pengujian Bahan Susun Campuran Beton}

Pada tahap ini dilakukan dan pemeriksaan bahan penelitian yaitu Semen, Agregat, Serat Eceng gondok dan Beton. Pemeriksaan dilakukan untuk mengetahui sifat - sifat bahan apakah memenuhi standart spesifikasi yang telah di tentukan. Pengujian bahan susun campuran beton dengan menggunakan standar yang telah ditetapkan dan berlaku di Indonesia terdiri dari :

a) Penyelidikan Bahan Semen :

1. Percobaan Konsistensi Normal Semen (ASTM C 187-86)

2. Percobaan Berat Jenis Semen (ASTM C 188-89)

3. Percobaan Waktu Mengikat dan Mengeras Semen (ASTM 119-92)

b) Penyelidikan Bahan Pasir :

1. Pengujian Kadar Air Agregat (ASTM C 556 - 89)

2. Percobaan Berat Jenis Pasir (ASTM C 128-93)

3. Percobaan Air Resapan Pasir (ASTM C 128-93)

4. Percobaan Bobot Isi dan Rongga Udara (ASTM C 188-89)

5. Percobaan Analisa Saringan Pasir (ASTM C 136-95a)

c) Penyelidikan Bahan Batu Pecah

1. Percobaan Kelembapan Batu Pecah (ASTM C 566-89)

2. Percobaan Berat Jenis Batu Pecah (ASTM C 127-88-93)

3. Percobaan Air Resapan Batu Pecah (ASTM C 127-88-93)

4. Percobaan Berat Volume Batu Pecah (ASTM C 29-91)

5. Percobaan Analisa Saringan Batu Pecah (ASTM C 136-95a)

d) Pemeriksaan Serat Eceng gondok

Serat eceng gondok yang digunakan adalah eceng gondok yang diproses sendiri oleh peneliti sehingga menjadi serat eceng gondok yang dibutuhkan.

\subsection{Tahap Pembuatan Serat dari Enceng Gondok}

1. Pengambilan enceng gondok dari daerah sungai di Kecamatan Deket Kabupaten Lamongan.

2. Pembersihan enceng gondok dengan air bersih.

3. Eceng gondok dipotong-potong antara $5-10 \mathrm{~cm}$ 
4. Setelah enceng gondok dipotong-potong kemudian eceng gondok di gilingkan di tempat penggilingan.

5. Selesai digilingkan, kemudian serat eceng gondok dijemur sampai benar-benar kering. Variasi penambahan serat eceng gondok yang digunakan sebesar $0 \%, 1 \%, 3 \%$ dan $5 \%$ dari berat semen. Kemudian pembuatan benda uji dan penambahan serat eceng gondok pada masing - masing variasi dilakukan 3 kali sesuai dengan umur beton. Setiap pengujian terdapat 3 benda uji untuk setiap varian.

\subsection{Proses Perawatan Beton}

1. Setelah 24 jam dari proses pencetakan beton, cetakan beton dibuka perlahan-lahan dan benda uji silinder beton diambil

2. Benda uji kubus beton diletakkan dalam suatu bak air, dan dibiarkan sampai sehari sebelum waktu pengetesan untuk dikeluarkan dari bak (pengeringan)

3. Pada waktu pengetesan, benda uji yang telah dikeluarkan dari bak dan mengering ditimbang beratnya setelah itu diukur dimensinya

4. Kemudian benda uji dicapping / diratakan dengan larutan belerang pada bidang tidak rata

5. Permukaan yang dicapping dari benda uji diletakkan di atas, dan benda uji siap dites Langkah tersebut berlaku untuk benda uji yang berumur 7 hari.

\section{HASIL DAN PEMBAHASAN}

Berdasarkan metode pengujian referensi standart yang berlaku, penulis melakukan pengujian di Laboratorium Universitas Islam Lamongan (UNISLA). Pengujian karakteristik material halus dan kasar merupakan pengujian awal yang di lakukan agar mengetahui karakteristik agregat halus dan kasar sebelum melakukan mix design beton yang mengacu pada SNI.

Dari data yang telah diperoleh selama pengujian, maka dilakukan perencanaan rancang campur (Mix Design SNI 03-2834-2000) pada beton dengan memanfaatkan serat alami eceng gondok, dalam pengujian tersebut beton merujuk pada beton mutu sedang dengan prosentase bervariasi pada komposisi semen yang dikurangi oleh serat alami eceng gondok. Benda uji yang digunakan adalah silinder dengan ukuran tinggi $30 \mathrm{~cm}$ dan diameter $15 \mathrm{~cm}$ sebanyak 3 buah untuk setiap sample campuran beton untuk diujikan kuat tekan beton pada umur 7 hari. Diharapkan dari hasil penelitian ini, peneliti dapat mengetahui hasil kuat tekan beton

\subsection{Pencampuran Beton Segar (Mix Design) Data Perencanaan}
1. Deviasi standart
: Beton Non Struktural
2. Jenis semen
: Semen portland 
3. Jenis serat $\quad$ : Serat alami eceng gondok

4. Jenis agregat kasar : Kerikil

5. Jenis agregat halus : Pasir

6. Mutu beton : : Beton Non Struktural

7. Umur perawatan : 7 hari

8. Jenis benda uji : Silinder

Diketahui - Tinggi silinder $=30 \mathrm{~cm}$

- Diameter silinder $=15 \mathrm{~cm}(\mathrm{r}=7,5 \mathrm{~cm})$ Maka

Volume silinder $\quad=\pi \times \mathrm{r}^{2} \times \mathrm{t}$

$$
\begin{aligned}
& =3,14 \times 7,5^{2} \times 30 \\
& =529,75 \mathrm{~cm}^{2} \\
& =5299 \times 10^{3} \mathrm{x} \mathrm{m}^{3} \\
& =0.0053 \mathrm{~m}^{3}
\end{aligned}
$$

\subsection{Pengujian Beton dan Kuat Tekan Beton}

Sebelum pengujian beton keras dilakukan terdapat proses perendaman beton selama 7 hari. Perendaman ini dilakukan setelah benda uji dilepas dari cetakan. Setelah dilepas dari cetakan benda uji akan di keringkan dengan cara dijemur dan dilakukan penimbangan. Dan proses terakhir yaitu pengujian benda uji dengan mesin concrete compression machine.

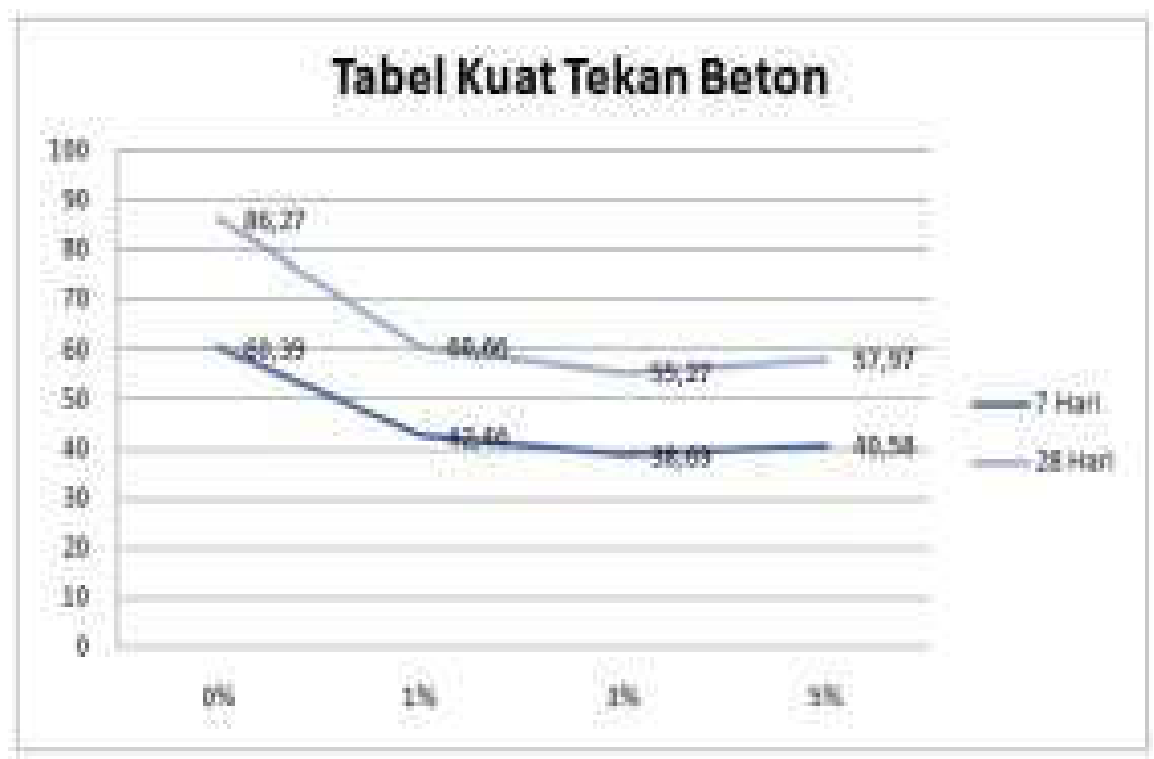

Gambar 1: kuat tekan tekan beton umur 7 hari dan 28 hari

Sumber : Hasil Penelitian, 2018 
Diketahui pada penelitian bahwa terjadi penurunan kuat tekan beton pada penambahan serat enceng gondok variasi $0 \%, 1 \%$ dan 3\% namun mengalami kenaikan pada 5\% setiap penambahan serat eceng gondok sehingga di dapat nilai kuat tekan tertinggi pada beton yang dicampur dengan serat eceng gondok $1 \%$ umur beton ke 7 hari yaitu $42,46 \mathrm{~kg} / \mathrm{cm} 2$ dan kuat tekan beton terendah terdapat ada beton yang dicampur serat eceng gondok $4 \%$ umur beton ke 7 hari yaitu $40,58 \mathrm{~kg} / \mathrm{cm} 2$. Diketahui pada penelitian bahwa terjadi penurunan kuat tekan beton pada penambahan serat enceng gondok variasi $0 \%$ umur 28 hari adalah 86,27, 1\% umur 28 hari adalah $60,66,3 \%$ umur 28 hari adalah $55,27,5 \%$ umur 28 hari adalah 57,97 mengalami penurunan di variasi $1 \%$ dan $3 \%$ namun mengalami kenaikan pada $5 \%$.

Tabel 1: Pengujian Kuat Tekan beton umur 28 hari

\begin{tabular}{|c|c|c|c|c|c|c|c|}
\hline$N_{0}$ & $\begin{array}{l}\text { Kode } \\
\text { Beton }\end{array}$ & $\begin{array}{l}\text { Umur } \\
\text { beton }\end{array}$ & $\begin{array}{l}\text { Nilai } \\
\text { korelasi }\end{array}$ & $\begin{array}{c}\text { Teganagana } \\
\text { Haucur } \\
\text { (kg/cmit) }\end{array}$ & $\begin{array}{c}\text { Teg, } 18 \\
\text { bari } \\
\left(\mathrm{hg} / \mathrm{cm}^{4}\right)\end{array}$ & $\begin{array}{l}\text { Tegangan hancur } \\
\text { umur } 28 \text { hari (Mpa) }\end{array}$ & rata-rata \\
\hline 1 & $\mathrm{~B} 0 \%$ & Hari & 0,70 & 62,28 & 88,97 & 7,38 & \multirow{3}{*}{7,16} \\
\hline 2 & $\mathrm{~B} 0 \%$ & 7 Hari & 0,70 & 53,79 & 76,84 & 6.38 & \\
\hline 3 & B0\% & 7 Hari & 0,70 & 65,11 & 93,01 & 7,72 & \\
\hline 4 & $\mathrm{~B} 1 \%$ & 7 Hari & 0,70 & 36,80 & 52,57 & 4,36 & \multirow{3}{*}{5,03} \\
\hline 5 & B1\% & 7 Hari & 0,70 & 45,29 & 64,71 & 5,37 & \\
\hline 6 & $\mathrm{~B} 1 \%$ & 7 Hari & 0,70 & 45,29 & 64,71 & 5,37 & \\
\hline 7 & B3\% & 7 Hari & 0,70 & 39,63 & 56,62 & 4,70 & \multirow{3}{*}{4,48} \\
\hline 8 & B $3 \%$ & 7 Hari & 0,70 & 36,80 & 52,57 & 4,36 & \\
\hline 9 & B3\% & Hari & 0.70 & 36.80 & 52.57 & 4.36 & \\
\hline 10 & B5\% & 7 Hari & 0,70 & 42,46 & 60,66 & 5,03 & \multirow{3}{*}{4,81} \\
\hline 11 & $\mathrm{~B} 5 \%$ & 7 Hari & 0,70 & 39,63 & 56,62 & 4,70 & \\
\hline 12 & B5\% & 7 Hari & 0,70 & 39,63 & 56,62 & 4,70 & \\
\hline
\end{tabular}

Sumber : Hasil penelitian, 2018

Dari hasil penelitian pada tabel 5.4 didapatkan hasil uji kuat tekan beton menunjukkan pada umur 28 hari dengan varian penambahan serat alami eceng gondok sebesar $0 \%, 1 \%, 3 \%$ dan $5 \%$ yang dilakukan di Laboratotium Teknik Sipil Universitas Islam Lamongan (UNISLA) sebagai berikut:

1. Dari hasil uji kuat tekan dengan campuran serat eceng gondok $0 \%$ dengan umur 28 hari di dapat nilai rata-rata dari 3 sampel 7,16 Mpa. 
2. Dari hasil uji kuat tekan dengan campuran serat eceng gondok 1\% dengan umur 28 hari di dapat nilai rata-rata dari 3 sampel 5,03 Mpa.

3. Dari hasil uji kuat tekan dengan campuran serat eceng gondok 3\% dengan umur 28 hari di dapat nilai rata-rata dari 3 sampel 4,48 Mpa

4. Dari hasil uji kuat tekan dengan campuran serat eceng gondok 5\% dengan umur 28 hari di dapat nilai rata-rata dari 3 sampel 4,81 Mpa.

\section{KESIMPULAN}

\subsection{Kesimpulan}

Dari data yang diperoleh dan dari analisa data yang telah dilakukan maka dapat diambil kesimpulan sebagai berikut :

a) Ketika campuran beton tersebut diberi tambahan serat enceng gondok pada variasi $1 \%$ dengan umur 28 hari sebesar $60,66 \mathrm{~kg} / \mathrm{cm} 2$ telah mengalami penurunan dan menurun kembali pada variasi $3 \%$ dengan umur 28 hari sebesar $55,27 \mathrm{~kg} / \mathrm{cm} 2$ tetapi mengalami kenaikan pada variasi $5 \%$ dengan umur 28 hari sebesar $57,97 \mathrm{~kg} / \mathrm{cm} 2$.

b) Dari data diatas dapat disimpulkan bahwa serat eceng gondok dapat di pakai dalam campuran beton dan dibutuhan penelitian lebih dalam lagi untuk mengujinya.

\subsection{Saran}

Berdasarkan hasil penelitian, penulis menyadari masih banyak kekurangan pada penelitian ini, oleh karena itu hasil penelitian ini belum dapat dikatakan sempurna, namun demikian diharapkan dapat memberikan kontribusi bagi mahasiswa/i dalam rangka pembelajaran. Ada beberapa hal yang dapat dipelajari pada penelitian ini dan dapat dilakukan lebih lanjut sebagai acuan atau masukan yang dapat berguna bagi mahasiswa/i atau peneliti lain dan bagi lembaga pendidikan perguruan tinggi, diantara nya adalah:

1. Dalam penelitian selanjutnya pengolahan eceng gondok seharusnya diubah menjadi bahan anorganik sehingga penyerapan air bisa berkurang.

2. Untuk menjaga dan menetapkan kualitas mutu beton yang direncanakan, mahasiswa harus sudah mengetahui kualitas bahan yang digunakan.

3. Agar diperoleh nilai slump yang sesuai dengan yang diharapkan maka pada saat pengetesan slump harus diperhatikan dengan benar prosedur pelaksanaan nya.

\section{REFRENSI}

[1] ASTM,Annual Book of ASTM Standart Volume 04.02 "Concrete and 
Aggregates", 2001

[2] ASTM C 29-91, Standard Test Method for Bulk Density ("Unit Weight”) and Voids Aggregates.

[3] ASTM C 33-01, Standart Specification For Concrete Agregate. Philadelphia

[4] ASTM,C39, Compresive Strength of Cylindrical Concrete Specimens, (2002). Annual Books of ASTM Standards, Philadelphia-USA.

[5] ASTM C 127, Standard Test Method for Density, Relative Density (Specific Gravity), and Absorbtion of Coarse Aggregate.

[6] ASTM C 128-78, Standard Test Method for Density, Relative Density (Specific Gravity), and Absorbtion of Fine Aggregate.

[7] ASTM C 187-86, Normal Consistency of Hydraulic Cement

[8] ASTM C 188-89, Density Test of Hydraulic Cement

[9] ASTM C 188 - 95, Standard Test Method for Density of Hydraulic Cement.

[10] ASTM C 191-92, Time of Setting of Hydraulic Cement by Vicat Needle

[11] ASTM C 566 - 89, Standard Test Method for Total Evaporable Moisture Content of Aggregate by Drying

[12] Badan Standarisasi Nasional. (2000). SNI 03-2834-2000, Tata Cara Pembuatan Rencana Campuran Beton Normal.

[13] Badan Standarisasi Nasional.. Hidayat, 2011. Pengaruh Penambahan Abu Sekam Padi Terhadap Kuat Tekan Beton K-225. Jurnal Aptek Edisi 2, Vol

[14] Universitas Pasir Pengarai, Riau. Tjokodimuljo, Kardiyono. 2004. Tegnologi Beton. Nafiri, Yogyakarta

[15] Fakultas Teknik Sipil, Pedoman Praktikum Beton, laboratorium Struktur Universitas Islam Lamongan. 